\title{
Interação verbal nos cursos de ensino a distância: vínculos e autonomia.
}

\author{
Cimara Apostólico
}

\begin{abstract}
Mestre em Comunicação e Semiótica pela PUCSP. em 2006. Especialista em Língua Inglesa, pela USP em 2004. Especialista em Ead e logística. Graduada em Letras. Profa. inglês, espanhol e alemão. Autora de aulas virtuais e projetos. Tutora e orientadora do curso de logística. Pesquisadora da fábrica de artigos da Revista Eniac Pesquisa desde 2009. Avaliadora por notória especialidade de trabalhos científicos, organizadora dos seminários e e avaliadora e revisora dos Anais.
\end{abstract}

\section{Resumo}

Este artigo tem a finalidade de discutir a tríade interação verbal, afetividade e autonomia como base para aprendizagem nos cursos de ensino a distância. O professor como mediador entre o conhecimento e o aluno deve elaborar metodologias, que facilitem a assimilação do conteúdo pelos discentes. Não se trata, portanto, de corrigir prontamente as atividades e enviar comentários coletivos; significa antes entender que cada aluno tem uma maneira particular de aprender e necessita de uma intervenção individualizada, que otimize seu tempo de aprendizado para que ele consiga lidar com as solicitações do curso no mínimo tempo possível, uma vez que uma das principais razões que faz com que o aluno opte pelos cursos de ensino a distância é o pouco tempo para realizar atividades. Essas questões serão abordadas por meio de pesquisas bibliográficas de caráter qualitativo, sendo fundamentadas, principalmente, por Piaget e Vygotsky, que tratam sobre os aspectos afetivos e sociointeracionistas para a formação cognitiva; pela abordagem de Pedro Demo acerca da autonomia e com o apoio de Bakhtin para entendermos mais sobre interação verbal.

Palavras-chave: interação verbal, afetividade, autonomia, educação a distância.

\section{Abstract}

The article aims to discuss the triade verbal interaction, affection and autonomy as a basis for learning in distance education courses. The teacher as a mediator between knowledge and the student, he must develop methodologies that facilitate the assimilation of content by students. Therefore it is more than correct the collective activities and submit comments; means first understand that every student has a particular way of learning and requires an individualized intervention that optimizes your learning time, so that he can cope with the demands of the course in the minimum possible time, considering that the main reasons that makes 
the student chooses courses by distance learning is little time to perform activities. These issues will be addressed through literature searches qualitative, being based mainly on Piaget and Vygotsky, who deal on the affective aspects and sociointeractionists for cognitive training; approach by Pedro Demo concerning autonomy and with the support of Bakbtin to understand more about verbal interaction.

Keywords: verbal interaction, affection, autonomy, distance education

\section{Problema da pesquisa:}

Os cursos de educação a distância visam promover oportunidades de aprendizado e crescimento para indivíduos que não podem frequentar cursos presenciais devido ao fator geográfico e/ou falta de tempo.

Constata-se que há grande número de alunos que evadem nesses cursos e o primeiro aspecto apontado por eles é a falta de tempo. Há alguma assessoria que possa ser dada pelo professor mediador no sentido de ajudar o aluno a se organizar melhor na questão tempo para lidar com mais conteúdo em menos tempo?

\section{Introdução}

A modalidade de ensino a distância, presente no Brasil há mais de 30 anos, encontra ainda resistência e diversos opositores, estranhamente, também, por aqueles que não podendo estudar presencialmente, são forçados a optar por cursos a distância.

A evasão nesse segmento "acontece precocemente, e $90 \%$ dos que desistem o fazem antes da metade do curso. Pesquisa aponta como motivo principal a disputa com o relógio, mais grave do que a falta de dinheiro" (ABED, 2010, p.25).

É de conhecimento geral que um dos maiores problemas enfrentados por nossa sociedade é o tempo, ou melhor, a falta dele. Estamos em constante luta, buscando "otimizar" nossas atividades; procurando realizar ações concomitantes para aproveitar melhor nossas horas diárias. O mesmo fator (tempo) que impulsiona o indivíduo a buscar cursos de ensino a distância, ironicamente conduz à desistência.

Nesse sentido, torna-se fundamental a realização de estudos, que visem encontrar maneiras de facilitar $O$ aprendizado para o aluno, fazendo com que ele consiga aprender mais, utilizando menos tempo.

Cabe mencionar que a questão é bastante complexa, por isso é fundamental refletir um pouco mais para que não 
visualizemos apenas a ponta do iceberg, que, neste momento, se apresenta como "tempo".

As relações: interação verbal, afetividade e autonomia podem ser alicerces na construção do conhecimento, pois o aluno precisa de estímulos, que o motivem a continuar nessa trajetória, que sabemos é extensa tanto para cursos presenciais como para cursos a distância.

\section{Hipóteses}

No ensino a distância, um dos problemas enfrentados pelos professores são as salas virtuais cada vez mais cheias e o pouco tempo para conhecer os alunos e dedicar atenção às dificuldades de compreensão do conteúdo e tempo de aprendizado que não coincidem.

O ensino a distância, em teoria, deveria aproximar os distantes geograficamente, todavia, há a questão da interação que não se estabelece, uma vez que os alunos matriculados na mesma sala praticamente não se conhecem. Uma oportunidade de conhecimento ocorre por meios dos fóruns, mas devido ao fato de não estabelecerem laços anteriores, torna-se desinteressante interagir com $\mathrm{O}$ "desconhecido". Nesse contexto, o único laço do aluno é o professor mediador/professor tutor, que está sobrecarregado, tornando a interação limitada a breves respostas, que podem não atender as necessidades $\mathrm{e}$ as expectativas do aluno.

Sabendo-se que o sociointeracionismo (Vygotsky) - imprescindível para o aprendizado - não ocorre, é preciso propiciar condições para que os alunos obtenham êxito no curso. Para que haja a relação aluno/conteúdo/aprendizado é essencial a autonomia, que será o norteador para que o estudante consiga traçar metas e estratégias para aprender, sem depender exclusivamente do professor, que passa a ser mediador, uma vez que há um aluno maduro com autossuficiência para o aprendizado.

\section{Justificativa}

É do conhecimento geral que uma das maiores dificuldades nos cursos de ensino a distância é a falta de habilidade leitora dos indivíduos. $\mathrm{O}$ entendimento do texto requer uma trajetória rica em experiências, uma vez que o texto precisa do leitor para fazer sua parte (ECO, 2003). O texto depende do leitor e viceversa, isso quer dizer, que ambos: texto e leitor interagem, a relação é dinâmica e a significação é encontrada tanto no texto como no leitor. Assim, é preciso "rechear 
a trajetória de mundo" do aluno para que ele consiga depreender do texto o maior número de informações.

Apesar de os jovens estarem habituados com a internet pelo uso de redes sociais como facebook, twiter, MSN dentre outras, grande parte das interações situam-se no nível do cotidiano com elementos informativos superficiais, o que gera uma limitação quando se trata de outras estruturas. Fazendo justiça às redes sociais é importante lembrar que elas são fundamentais para troca de experiências e reflexões - é uma maneira de se comunicar, que favorece aos mediadores maior entendimento do perfil do grupo.

\section{Metodologia}

Considerando a subjetividade do tema escolhido e a dificuldade em mensurar as análises de maneira pontual, foi feita a opção pela metodologia qualitativa analítica de caráter documental e com base em bibliografias, por meio de análise de dados secundários, provenientes de textos científicos e bibliografias no intuito de recuperar o modelo conceitual. A pesquisa exploratória será facilitador para trazer à tona a discussão, com vistas a tornar mais objetivo e claro o levantamento das hipóteses.

\section{Capítulo 1: Os Vínculos: Afeto- Aprendizagem.}

Diversos teóricos da Educação dissertam a respeito da importância da afetividade para o aprendizado infantil. A afetividade deve ser trabalhada a partir da infância e é extensível à fase adulta. Os indivíduos precisam estar integrados ao ambiente para que se promova o aprendizado; é fundamental sentir-se parte do processo. Cunha afirma que:

$$
\begin{aligned}
& \text { Percebe-se que, quando se fala em } \\
& \text { fracasso na educação, é porque durante } \\
& \text { décadas o afeto ficou fora da sala de aula, } \\
& \text { proporcionando o tecnicismo, a dicotomia } \\
& \text { entre razão e emoção, o reducionismo } \\
& \text { arbitrário e a aferição do valor do } \\
& \text { conhecimento mais pelo seu } \\
& \text { individualismo poder de trânsito do que } \\
& \text { pelo seu poder de satisfação pessoal no } \\
& \text { compartilhar de saberes. (CUNHA, } \\
& \text { 2010, p. 30). }
\end{aligned}
$$

Em uma era tecnológica, na qual se utiliza seu principal aparato - o computador, como ferramenta de aprendizado, era previsível que a relação professor-alunoaprendizado ocorresse de maneira dissociada da emoção, mesmo com a possibilidade do ensino 'face a face a distância", ainda assim, esse olhar para o outro representa o aperfeiçoamento da mídia e não a mudança das bases tecnicistas. 
Piaget afirma que, apesar de distintas, a vida afetiva e a cognitiva são inseparáveis:

$O$ que o senso comum chama de
'sentimentos' enteligência',
considerando-os como duas faculdades
opostas entre si, são simplesmente as
condutas relativas às pessoas e as que se
referem a ideias ou coisas; mas em cada
uma dessas condutas intervêm os mesmos
aspectos afetivos e cognitivos da ação,
aspectos sempre reunidos de fato e que,
portanto, não caracterizam de modo
algum faculdades independentes.
(PLAGET, 1983, pág.16)

Com base no exposto, é possível compreender que dentro da complexidade que envolve a aprendizagem, os aspectos cognitivos e emotivos estão imbricados, o aluno, portanto, precisa encontrar no objeto algum elemento que o seduza, que desperte sua vontade de interagir.

$\mathrm{Na}$ sala de aula presencial, esta vontade não se encontra necessariamente no sujeito; pode ser estimulada por meio de um colega, que instigue ao debate, à troca de ideias; pode ser encontrada em um professor, que desperte a atenção pelo fato de ser simpático e/ou até mesmo inquiridor, enfim, são muitas variáveis que não cabem discutir no momento.

No ensino a distância, “a natureza interativa das mídias utilizadas influi diretamente na quantidade e qualidade do diálogo que se estabelece entre professores e alunos" (MAIA \& MATTAR, 2007, pág.15). É como se as mídias atuassem como "substitutas dos colegas de classe", todavia, é fundamental a reflexão de que em função de seu caráter mecânico, a mídia não desperta uma predisposição para a ação.

Maia e Mattar estabelecem separação entre mídias como livros, vídeos e programas de rádio e televisão e a internet, que segundo eles, estabelece maior nível de interação:

(...) a Internet possibilita elevado nível de interação, um diálogo intenso e dinâmico, por meio de ferramentas como fóruns e chats, assim como vídeo conferências pelas quais os alunos podem participar com comentários. A manipulação das mídias permite ampliar o diálogo entre alunos $e$ professores e, em consequência, diminuir a distância transacional e a sensação psicológica de separação, gerando um senso de comunidade. (MALA \& MATTAR, 2007, pág. 15).

É do indivíduo essa necessidade de pertença ao grupo e a sensação psicológica de separação pode ser parcialmente suprida pela inovação de mídias na internet, mas ela resolve parcialmente a questão da interação.

Os cursos online têm como característica a velocidade, não oferecendo, pois, condições para extensas interações e 
reflexões nos fóruns. Há casos em que as pessoas partilham o mesmo espaço, porém, as respostas são fornecidas sem se considerar a fala do outro, não há busca por complementar ou opor com argumentos o que foi explicitado e, mais uma vez nos deparamos com a questão cognição/emoção. É possível afirmar, com base na experiência, que os fóruns são mais interativos, quando os envolvidos se conhecem.

Retomando ao conceito de Piaget, emoção e cognição são faculdades independentes, porém, caminham simultaneamente, desta maneira, o aluno na plataforma virtual precisa ser 'envolvido' para a formação da estrutura do aprendizado naquele ambiente.

O conhecimento precisa de autonomia para se constituir mais solidamente, é o que procuraremos entender a seguir.

\section{Capítulo II:}

A Construção Da

\section{Autonomia}

A educação a distância é um ambiente novo para muitos indivíduos, que sentem dificuldades, principalmente por terem que se confrontar com situações novas. Piaget explica que diante dessas circunstâncias, o indivíduo primeiro tateia. "Esse tateio pode ser puramente sensório-motor ou se interiorizar sob a forma de 'tentativas' apenas do pensamento; mas sua função é sempre a mesma: criar soluções, que a experiência irá selecionar com o passar do tempo". (PIAGET, 1983, pág.99)

O encontro das soluções faz com que os indivíduos se adaptem a circunstâncias e consequentemente sintam-se mais confortáveis. Deve-se, entretanto, ressaltar que nessa busca são importantes tempo e experiência; tempo é exatamente o que falta nos cursos de ensino a distância, por isso a importância de desenvolver a autonomia, para que o sujeito agente tenha condições de autoorganização, para que seja capaz de levantar hipóteses e buscar metodologias para o seu aprendizado. Carmem Maia e João Mattar destacam que:

$$
\begin{aligned}
& \text { (...) mesmo com o progresso das } \\
& \text { tecnologias, muitos modelos de EaD } \\
& \text { privilegiam o estudo autônomo e } \\
& \text { independente, utilizando muito poucas } \\
& \text { atividades interativas, porque essas } \\
& \text { atividades, ainda que assincronas, em } \\
& \text { geral provocam restrições de tempo para o } \\
& \text { aluno, o que iria contra o próprio espírito } \\
& \text { da aprendizagem a distância. (MALA } \\
& \& M A T T A R, 2007, \text { pág. 9). }
\end{aligned}
$$

O conceito "autonomia" é tratado como se essa característica fosse inata ao indivíduo; quando, de fato, educar pela 
pesquisa supõe, conforme Pedro Demo (2011, pág.39) “cuidados propedêuticos, decisivos no professor e no aluno, por conta da qualidade educativa que a formação da competência formal e política implicam". Podemos entender que autonomia é uma conquista, é um status que pode ser alcançado pelo aluno a partir de intervenções dos professores. Dentre algumas condições para alcançar essa qualidade, Demo (2011) explícita o desenvolvimento da capacidade de saber pensar, de cultivar o aprender a aprender e saber avaliar-se e avaliar a realidade.

Esses três elementos, conforme mencionado, não são inerentes ao indivíduo - é possível desenvolvê-los, por essa razão, é importante a revisão curricular, incluindo, por exemplo, uma disciplina como métodos de estudos, que visem facilitar o pensar, o aprender e o avaliar; ajudando o aluno a se orientar nesse novo ambiente, fornecendo condições para que consiga prosseguir "sozinho".

Ensinar a caminhar por si é um dos fatores que podem reduzir o índice de evasão e diminuir a sensação psicológica de separação e mais que isso, pode trazer luz ao entendimento de que autonomia não é sinônimo de solidão e autossuficiência, mas se relaciona às possibilidades de navegar com confiança pelos ambientes e dialogar com os diversos assuntos, tornando-os mais próximos, rompendo com o superficial conceito de texto (tecido) como decodificação; a relação é dinâmica, coexistimos com as várias questões afetamos e somos afetados, independentes da mídia escolhida, afinal somos agentes do processo de aprendizagem. Andrade e Vicari (2006, pág.259) corroboram explicitando que "o sujeito só aprende a conhecer-se mediante sua ação sobre os objetos". Cabe ressaltar também que a maneira de pensar é peculiar a cada indivíduo, conforme Demo:

$$
\begin{aligned}
& \text { O caráter não linear complexo da } \\
& \text { aprendizagem pode ser visualizado em } \\
& \text { sua tessitura reconstrutiva política, em } \\
& \text { primeiro lugar. Tomando em conta a } \\
& \text { extrema diversidade dos processos } \\
& \text { evolucionários em sentido geral e } \\
& \text { particular, nenhum cérebro é igual ao } \\
& \text { outro e muito menos funciona da mesma } \\
& \text { forma que o dos outros ... Cada indivíduo } \\
& \text { é, ao mesmo tempo, igual e diferente. É } \\
& \text { igual, porque na linhagem biológica é } \\
& \text { apenas um membro a mais dentro de sua } \\
& \text { identidade dinâmica. É diferente, porque } \\
& \text { desenvolve personalidade própria } \\
& \text { irrepetivel. (DEMO, 2002, p.135) }
\end{aligned}
$$

O conhecimento permite reflexão para a mudança e, consequente, reconstrução. Pela razão de os indivíduos serem iguais e diferentes, a interação é imprescindível para essa reconstrução; a linhagem 
biológica é secundária em relação ao processo dinâmico de trocas, que constituem a personalidade do indivíduo, pois “o pensamento dirigido é social. À medida que se desenvolve, vai sendo cada vez mais influenciado pelas leis da experiência e da lógica propriamente dita”. (Vygotsky, 1991, pág.11).

O empirismo considera que o indivíduo adquire conhecimento por meio da experiência e da observação, conceito que deve ser considerado como integrante da complexidade que envolve a aprendizagem, mas que solicita a mediação proposta por Vygotsky, nas palavras de Andrade e Vicari (2006, pag.259) "o indivíduo modifica ativamente a situação estimuladora como parte do processo de resposta... Trata-se de uma aprendizagem social que considera os processos cognitivos que ocorrem durante a interação". Afetividade e autonomia propiciam interações mais dinâmicas, considerando que o aluno torna-se parte do todo, é agente e está apto a promover mudanças, todavia para sedimentação desses dois elementos é imprescindível o papel mediador estabelecido pela interação verbal.

\section{Capítulo 3: Interação Verbal}

Para uma comunicação eficaz, é fundamental que o professor mediador conheça os seus interlocutores e considere que a comunicação não se limita aos elementos: emissor, receptor, mensagem; isto significa afirmar que não se trata de enviar respostas corretas, mas de compreender que o discurso, por sua característica ideológica (Bakhtin, 2006), está carregado de significados, portanto, há de ser cauteloso quanto à maneira como se responde aos questionamentos que surgem pelos alunos.

O domínio do conteúdo é importantíssimo, porém, é parte de uma categoria maior que insere o indivíduo como integrante no processo de cognição, assim, Informação; como é realizada a transmissão e, principalmente, o entorno: as implicações que circundam o aluno para apreensão do conhecimento - são questões que devem ser tratadas com mais seriedade para evitar ambiguidades nas interações realizadas no ambiente virtual.

Outro cuidado a ser tomado é o de evitar a sensação de monólogo experimentada por muitos alunos nesse ambiente. Quanto à monologia, Bakthin indaga a maneira como se apresenta a enunciação monológica do ponto de vista do subjetivismo individualista. $\mathrm{E}$ complementa: "Vimos que ela se 
apresenta como um ato puramente individual, de seus desejos, suas intenções, seus impulsos criadores, seus gostos, etc. (BAKHTIN, 2006, pág. 115)".

O Ensino a distância, devido, principalmente, ao grande número de alunos na sala virtual com quem $O$ professor precisa lidar, corre o risco de se tornar monológico e nesse sentido, não há crescimento, não ocorre aprendizagem, por isso é relevante comentar sobre expressão.

Bakhtin explica sobre esse conceito e afirma que é uma categoria geral, de nível superior que engloba o ato de fala, a enunciação. Ele define expressão como: “... tudo aquilo que, tendo se formado e determinado de alguma maneira no psiquismo do indivíduo, exterioriza-se objetivamente para outrem com a ajuda de algum código de signos exteriores". (BAKTHIN, 2006, pág.115).

E acrescenta que toda teoria da expressão deve levar em conta duas facetas: “... o conteúdo (interior) e sua objetivação exterior para outrem (ou também para si mesmo)".

A escolha para objetivação exterior feita pelo professor mediador será propulsora para a aquisição da autonomia, pois conforme Bakhtin (2006) todo ato expressivo move-se entre as duas facetas: conteúdo interior e objetivação exterior. Desta forma, há uma interação entre professor e aluno, no sentido de construírem juntos discursos, que concebam as relações dialógicas necessárias para o efetivo aprendizado.

Nas questões dialógicas, o sujeito não é apenas influenciado pelo meio, mas também é agente, apto a promover transformação. Pela alteridade são constituídas as identidades; na relação "eu e o outro". Esse processo vem ao encontro da proposta sociointeracionista de Vygotsky - em que o conhecimento é adquirido no meio social e modificado pelo sujeito, de acordo com as condições que cercam o indivíduo.

O aprendizado ocorre quando o aluno age sobre o objeto e o modifica, por isso é fundamental que seja tocado por meio de questões dialógicas estabelecidas com os pares, principalmente com o professor mediador, que irá conduzir na busca por maior proximidade com as diversas questões que se apresentam.

Nesse sentido, o professor mediador ajudará na construção da tríade afeto, interação verbal e autonomia que são os alicerces para a aprendizagem.

\section{Considerações Finais:}


O ensino a distância possui a antagônica característica de manter distantes, fisicamente, professor-aluno e em paralelo estabelecer uma relação de proximidade, pois o contato passa a ser individualizado, quando dentro de um ambiente coletivo; compreende-se que cada indivíduo é único e precisa de uma devolutiva específica, que atenda seus conflitos.

Ao compreender as questões dialógicas que permeiam as relações, o professor mediador é capaz de perceber no discurso do outro quais caminhos devem ser indicados para a sensação de pertença no ambiente virtual e quais trajetórias conduzem ao interesse do aluno para que ele se sinta motivado a buscar autonomia por intermédio da pesquisa e passe a ser ele mesmo - agente do seu aprendizado, considerando sempre que todo texto precisa do leitor para ser e para ter significado.

Por essa pesquisa, tornou-se possível compreender mais ainda a importância do professor mediador no ensino a distância, que é a figura representativa do conhecimento.

\section{Referências:}

BAKHTIN, Mikhail M. Marxismo e filosofia da linguagem: problemas fundamentais do método sociológico da linguagem. 12 ed. São Paulo: Hucitec, 2006.

CUNHA, Antônio Eugênio. Afeto e aprendizagem: relação de amorosidade e saber na prática pedagógica. $2^{\mathrm{a}} \mathrm{ed}$. Rio de Janeiro: Wak Ed. 2010.

DEMO, Pedro. Complexidade e Aprendizagem: a dinâmica não linear do conhecimento. São Paulo: Atlas, 2002.

DEMO, Pedro. Educar pela pesquisa. 9 ed. Campinas, SP: Autores Associados, 2011.

ECO, Humberto. Seis passeios pelos bosques da ficção. 7.ed. São Paulo: Ed. Schwarcz, 2003.

GIL, Antonio Carlos. Métodos e Técnicas de Pesquisa Social. 6. ed. São Paulo: Atlas, 2010.

MAIA, Carmem e MATTAR, João. ABC da EaD: a educação a distância hoje. São Paulo: Pearson, Prentice Hall, 2007.

PIAGET, Jean. Problemas de Psicologia Genética.1. ed. Rio de Janeiro: Forense, 1973.

PIAGET, Jean. Psicologia da Inteligência. 2. Ed. Rio de Janeiro: Zahar, 1983.

SILVA, Marco (org.). ANDRADE, Adja F. e VICARI, Rosa M. Educação online: 2 ed. São Paulo: Loyola, 2003.VYGOTSKY,L.S. A formação social da mente: o desenvolvimento dos processos psicológicos superiores. 5.ed. São Paulo: Martins Fontes, 1996.

VYGOTSKY, L. Pensamento e Linguage m. 3.ed. São Paulo: Martins Fontes, 1991. 